Viso - Cadernos de estética aplicada Revista eletrônica de estética

ISSN 1981-4062

No 24, jan-jun/2019

http://www.revistaviso.com.br/
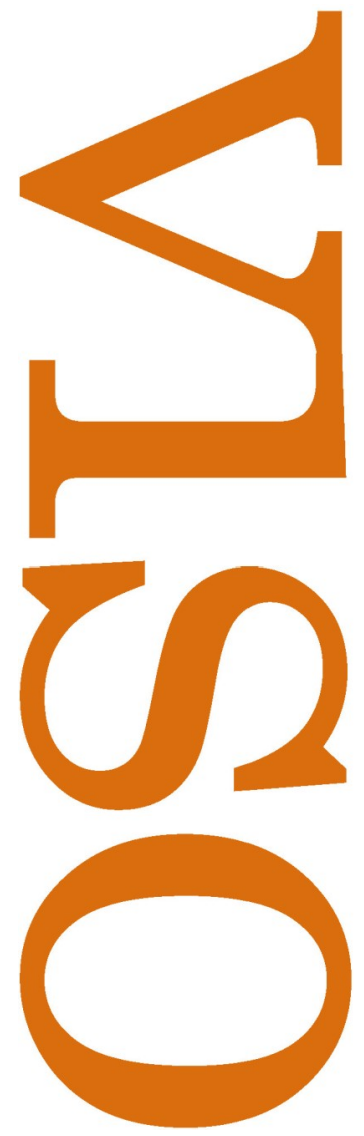

\title{
Ordinária poesis: a experiência na fotografia de Luiza Baldan \\ Michel Masson
}

Pontifícia Universidade Católica do Rio de Janeiro (PUC-RIO) 


\section{RESUMO}

Ordinária poesis: a experiência na fotografia de Luiza Baldan

Tendo como escopo a obra de Luiza Baldan produzida até o presente momento, este artigo procura investigar a relação entre lugar e imagem na prática fotográfica da artista. Para tanto, considera seu processo de produção, desvelado a partir de conversas, bem como assume a noção de experiência desenvolvida pelo filósofo John Dewey.

Palavras-chave: Luiza Baldan - fotografia - experiência - John Dewey

\section{ABSTRACT}

\section{Ordinary poesis: Experience in Luiza Baldan's Photography}

Having as scope the work of Luiza Baldan produced up to the present moment, this article seeks to investigate the relationship between place and image in the photographic practice of the artist. In order to do so, the author considers the production process of the artist, unveiled from conversations, as well resorts the notion of experience developed by the philosopher John Dewey.

Keywords: Luiza Baldan - photography - experience - John Dewey 


\section{MASSON, M. "Ordinária poesis: a experiência na fotografia de Luiza Baldan". In: Viso: Cadernos de estética aplicada, v. XII, n. 24 (jan-jun/2019), pp. 217- 233.}

DOI: $10.22409 / 1981-4062 / v 24 i / 318$

Aprovado: 05.08.2018. Publicado: 30.06.2019.

(C) 2019 Michel Masson. Esse documento é distribuído nos termos da licença Creative Commons Atribuição-NãoComercial 4.0 Internacional (CC-BY-NC), que permite, exceto para fins comerciais, copiar e redistribuir o material em qualquer formato ou meio, bem como remixá-lo, transformá-lo ou criar a partir dele, desde que seja dado o devido crédito e indicada a licença sob a qual ele foi originalmente publicado.

Licença: http://creativecommons.org/licenses/by-nc/4.0/deed.pt_BR

Accepted: 05.08.2018. Published: 30.06.2019.

(C) 2019 Michel Masson. This document is distributed under the terms of a Creative Commons Attribution-NonCommercial 4.0 International license (CC-BY-NC) which allows, except for commercial purposes, to copy and redistribute the material in any medium or format and to remix, transform, and build upon the material, provided the original work is properly cited and states its license.

License: http://creativecommons.org/licenses/by-nc/4.0/ 
Se a qualidade artística e estética está implícita em toda experiência normal, de que maneira explicamos como e por que ela geralmente não consegue explicitar-se? John Dewey

Seja o que for que ela dê a ver e qualquer que seja a maneira, uma foto é sempre invisível: não é ela que vemos.

Roland Barthes

Fachadas despretensiosas, cenas urbanas triviais, paisagens na estrada. Desde o início de sua trajetória artística, Luiza Baldan trilha percurso árduo, seguindo firme no contrafluxo das imagens apelativas do mundo. Distante do impacto imediato perseguido pelo fotojornalismo ${ }^{1}$, da natureza mercantil da imagem publicitária, bem como dos maneirismos e temáticas monumentais-espetaculares que predominam em grande parte da produção fotográfica contemporânea, Luiza investe, por via oposta, naquilo que há de mais comum: o material bruto da experiência cotidiana. Uma leitura apressada poderia concluir que se trata de imagens fáceis, sob pena de deixar escapar o cerne de sua inteligência poética. Obtidas a duras penas, elas são relativas à assimilação sensível dos lugares; dependem de um agudo senso perceptivo desenvolvido a partir de estratégias de interação com o ambiente. Ao fazê-lo, a artista opera em registro que se coaduna ao esforço teórico de John Dewey, qual seja, "restaurar a continuidade entre as formas refinadas e intensas que são as obras de arte e os eventos diários". ${ }^{2}$ No entanto, em princípio, Luiza vai além. Sua prática parece levar ao limite a relação entre experiência estética e experiência comum quando aparentemente as iguala. Em outras palavras, como alguém que estica uma corda, Luiza força os termos da equação de Dewey ao trabalhar com a matéria relativa à experiência diária em seu estado quase cru. Se para o filósofo "a arte tem a qualidade única de clarificar e concentrar significados contidos de maneira difusa e fraca em outras experiências"3, se ela "é prefigurada no próprio processo da vida"4, Luiza aposta na interação cotidiana não tanto como um modo incipiente de arte, mas como matéria estética potente e sutil, por isso mesmo, refinada. 


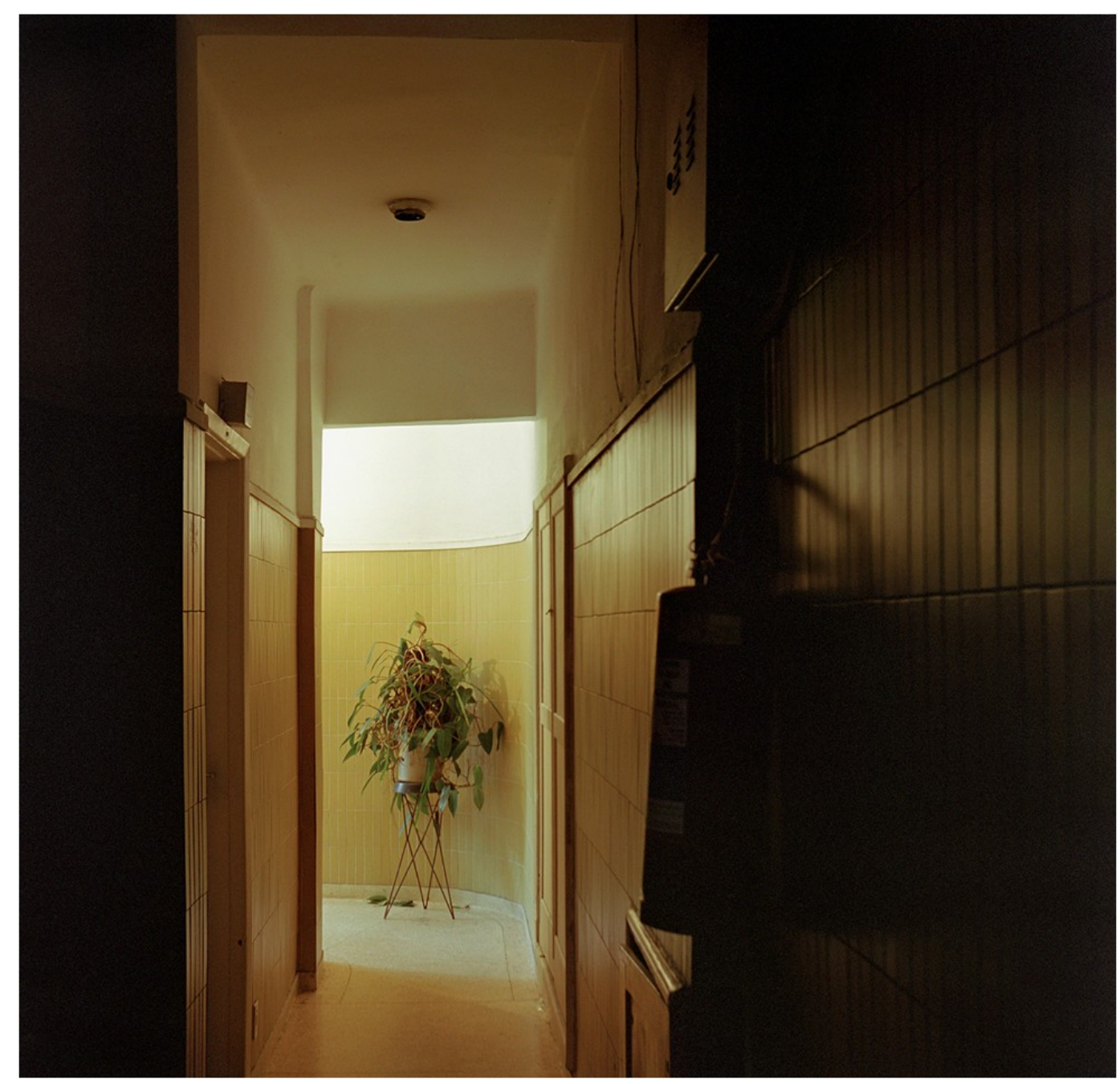

Sem Título (série Sobre umbrais e afins), 2004-2010, impressão a jato de tinta em papel-algodão, 100 x 100cm

Em Luiza, ato fotográfico e ato de expressão se confundem. A contrapelo, seu gesto consiste em selecionar, isolar, "retirar a camada que esconde a expressividade das coisas experimentadas". ${ }^{5}$ Dispersa em todos os cantos, obliterada, contudo, pela apatia e pelo torpor, a emoção estética é evocada pela artista em sua condição originária. Aqui e ali, sem julgamentos a priori, suas imagens recuperam o elã sensível inibido pelo hábito perceptivo, desarmado pela naturalização da experiência comum. Entregues de pronto, elas sinalizam nossa cegueira, acusam a esterilização dos nossos sentidos, colocando em jogo a predisposição afetiva ao apreço das coisas que tendemos a perder ao longo do tempo. Talvez por isso, seus corredores vazios e pouco iluminados a mim lembrem o bucólico aconchego que me acometia quando criança sempre que visitava o apartamento de minha avó, no Andaraí, com seu cheiro de passado. Recortes mundanos insuspeitos, as imagens de Baldan rememoram a condição atenta perdida, revivem sensações que potencializam o embate com o presente: são situações familiares autênticas e íntegras que emergem e revigoram a experiência sensível. Parafraseando Arthur Danto, elas menos transfiguram do que reapresentam lugares comuns. ${ }^{6}$ 
Luiza conhece os limites da imagem, sabe que ela é incapaz de subsumir uma experiência. Por isso, não procura reproduzir, mas, sim, redimensionar esteticamente, na clave da imagem, sua relação com o ambiente no curso do tempo. Não por acaso, trabalha com séries, ordena meticulosas estruturas, pensa no modo como o trabalho será exibido. Suas fotografias cartografam episódios corriqueiros, formam corpus, solicitam ao observador o olhar em conjunto, a percepção enquanto ação reconstrutiva e recriadora. Em algum grau, subvertem os termos de Rosalind Krauss, funcionando como signos indiciais que têm como referente não a circunstância objetiva literal ou os processos exteriorizados, visualmente verificáveis ${ }^{7}$, mas a experiência, sempre subjetiva e intransferível, que certos lugares proporcionam. Não obstante, Luiza escreve. A um só tempo descritivos e poéticos, seus textos procuram dar conta de impressões, sensações e observações suscitadas durante as vivências, funcionando, cada vez mais, como discurso suplementar que busca integrar-se e agregar camadas de informações às estruturas imagéticas. Eles ecoam os relatos de viagem dos artistas românticos do século XIX, e, às vezes, misturam-se ao discurso teórico ou à prosa do outro. Se em sua prática fotográfica Luiza recusa o aprisionamento do olhar, também sua produção textual não se quer condicionada por formatos prévios. Câmera como caderno de anotações, texto como imagem. Há algo na linguagem de Baldan da ordem de uma escrita visual.

\section{Cotidiano expressivo}

Da impessoalidade do corredor, me entrego à paisagem erma. ${ }^{8}$

Série fotográfica que remonta ao começo de seu aprendizado artístico em Miami ${ }^{9}$, Estados Unidos, Becos escapa à imagem-estereótipo da cidade: arquitetura déco e palmeiras-reais à beira-mar, pink flamingos e carros vintage. Esquivando-se de "fotografar lugares em que já se sabe o que se vai fazer ou se espera algo predeterminado"10, não por acaso, Luiza escolhe uma rua de serviço em South Beach, local onde predominam entradas destinadas aos funcionários de estabelecimentos comerciais, em sua maioria latinos. De imediato, Luiza associa a via secundária à lateralidade de sua condição de estrangeira. ${ }^{11}$ Acompanhada de um amigo, encampa busca obsessiva, fotografando quase diariamente, em horários variados, a arquitetura de fundos da grande cidade norte-americana. Fotografa o mesmo lugar repetidamente, voltando-se para elementos marcados pela negligência estética: respiradores, grades, encanamentos disfarçados com mãos de tinta. Modernistas e heterogêneas, suas referências vão desde a fotografia surrealista de Manuel Álvares Bravo ao formalismo construtivo de Geraldo de Barros. Se, por um lado, o resultado se faz como imagens que oscilam entre a atração pelo estranho e jogos formais de luz e sombra, por outro, vai-se consolidando a prática de observação da situação espacial, a ideia da fotografia menos como abstração do que como fundação de lugares. Em síntese, delineia-se o modelo de abordagem ainda hoje adotado pela artista: a vivência como recurso para "mudar a percepção acerca do lugar", "ver coisas novas num mesmo cenário". ${ }^{12}$ 


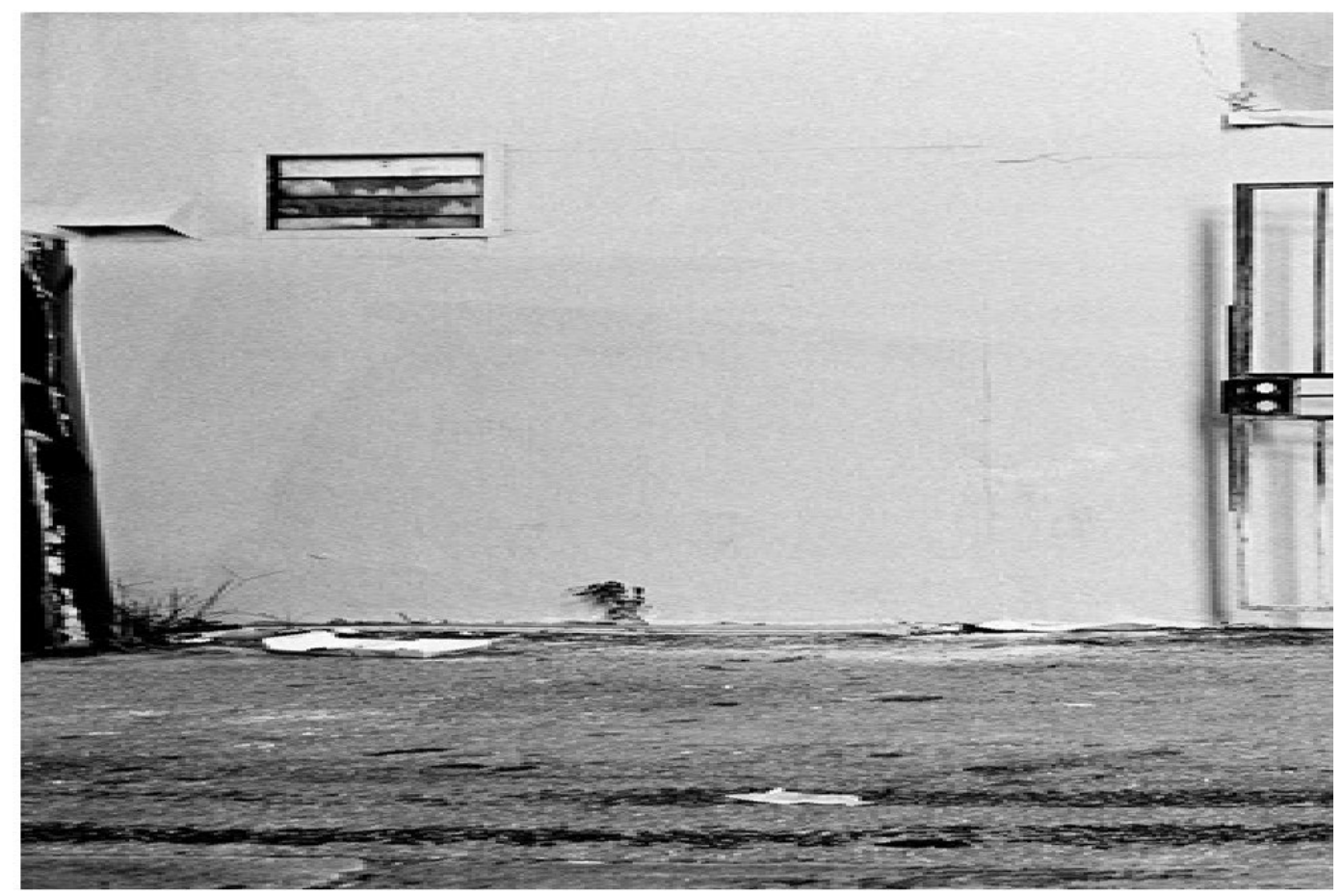

Sem Título (série Becos), 2000-2002, impressão em gelatina de prata com viragem a selênio, 40 × $60 \mathrm{~cm}$

Em meio às idas e vindas nesse não lugar $^{13}$, uma cena em especial se repete: um homem dormindo em um pequeno nicho na arquitetura. A cada vez que retorna, Luiza modifica seu enfoque, produzindo sequência fotográfica que, progressivamente, elimina a figura humana até sobrar apenas o abrigo improvisado. Reveladora, a atitude é sintomática, quase epítome de sua poética: Baldan evita a presença humana concreta para, em vez disso, trabalhar com indícios. Nesse sentido, o papelão que forra o piso, o gradil entreaberto ou a corda amarrada ao portão, atuam, todos, como vestígios sutis ${ }^{14}$ de ações contingentes e eventos banais. Daí o senso de pausa silenciosa e eventualmente de mistério que suas imagens ensejam. Luiza quer captar ambiências. Eximidas de pessoas, as fotografias procuram confrontar, sem mediações, observador e lugar. Está em pauta apropriar-se de um repertório mundano, de meios exteriorizados que são os elementos anônimos da arquitetura para, no entanto, agenciar o seu oposto: processos psicológicos íntimos e pessoais. Valem as imagens que registrem não a architecture parlante de Claude Nicolas Ledoux, premissa neoclássica da forma arquitetônica que autoexplicita sua função, mas o genius loci, o espírito do lugar em seus diversos ânimos, o modo sensível como vãos e paredes atuam na condição de agentes psicológicos, causando toda sorte de sensações: desconforto, acolhimento, desolação, nostalgia.

O interesse pelo suspense se acirra a partir de 2005 quando do retorno da artista ao Brasil. ${ }^{15}$ Tendo como referência a fotógrafa francesa Dolores Marat, na série Sobre umbrais e afins, Luiza lança mão de artifícios como penumbra e imagem desfocada, aos quais se alia o recurso do extracampo, noção cinematográfica relativa a imagens que, 
por conta do ocultamento, transportam o observador para espaços visualmente inacessíveis. Não obstante, inicia-se nesse período a pesquisa cromática de Baldan, que prossegue em séries como Pinturinhas e Diário urbano - a primeira, ao contrário de Umbrais, composta por imagens cujos recorte fechado e frontalidade cercam o olhar. Dito isso, se a sedução pela cor permanece por muito tempo - só recentemente sendo interrompida -, aos poucos o intenso cromatismo vai cedendo vez a colorações mais tênues, movimento que acompanha o distanciamento de Luiza em relação a interesses meramente formalistas. Mais e mais, fotografia é índice do que se pode apenas intuir: um acontecimento do qual se tem somente o rastro, um campo cego inacessível aos olhos, enfim, a experiência de um lugar.

Realizadas ao longo de períodos extensos, sem prazo de conclusão predefinido, as séries Umbrais, Pinturinhas e Diário urbano integram conjunto denominado pela artista projetos em andamento. Nelas, Luiza adota premissa presente em Becos, agora liberada do percurso repetido e da circunstância geográfica pré-delimitada: o exercício de observação, a prática do deslocamento constante para registrar, onde quer que estejam, os eventos encontrados pelo caminho, coisas que fazem parte do dia a dia mas que rompem com certos padrões, escapando à monotonia. Para tanto, é necessário manterse alerta, não vacilar, estar aberta aos momentos súbitos que oscilam entre a atenção e o acaso, quando algo inesperado ocorre e desperta os sentidos, trazendo à luz aquilo que insiste em permanecer oculto: vasos de plantas procurando levar a natureza para cantos sem vida, janelas servindo para a fuga do pensamento em momentos tediosos, entre outras tantas situações prosaicas. Eis a difícil tarefa de Baldan: fazer ver o notável comum, evidenciar os pequenos - porém vigorosos - deleites estéticos cotidianos ${ }^{16}$, desvelar, enfim, "a potência de significação inerente às coisas mudas", para usar os termos de Rancière. ${ }^{17}$

De natureza aberta, tais séries abrangem o período em que as coisas são observadas de uma determinada maneira pela artista. Em nada afeita ao simples colecionismo temático, Baldan realiza arquivos poéticos de alteridades urbanas. Criteriosamente organizados, cada corpo idiossincrático de imagens encarna um estado de espírito, e é esse registro afetivo específico que confere unidade ao todo. Dito de outra maneira, independente do lugar fotografado, permanece um modo sensitivo constante, o mundo revelado à imagem sensível do Eu. Há nisso algo de um expressionismo velado. Cifra de um estar-nomundo em trânsito, de comunicabilidade silenciosa, cada imagem espelha o processo inter-relacionado de agir e estar submetido a algo, a adaptação mútua entre sujeito e objeto; é o instantâneo de um acontecimento discreto, a um só tempo ordinário e poético: singularidades cotidianas isentas de exuberância; repletas, no entanto, de um lirismo comedido, à beira do inexpressivo.

Outro tipo de projeto levado a cabo é o daqueles com tempo determinado, que vão desde residências artísticas em edifícios até viagens no Brasil e no exterior. ${ }^{18} \mathrm{Em}$ tais "internações extremas" ${ }^{19}$, o objetivo é a imersão plena, a prolongada e contínua interação 
com as condições ambientes. A cada empreitada - impactante mesmo para Luiza, acostumada a mudar-se constantemente -, é colocada à prova a capacidade de adaptação ao desconhecido: entram em jogo a empatia e a desconfiança, o acolhimento e a hostilidade, tônicas de qualquer processo de chegada. "Um frio estranho porque me arranquei de casa para me entregar ao desconhecido. A ânsia que se transforma em prazer, gratidão e adrenalina. Cá estou outra vez na montanha-russa das novas paisagens". ${ }^{20}$ Caso emblemático, no Pedregulho a artista passa por processo de transformação pessoal ao se integrar em regime social de relações pautado em forte sentido comunitário. No edifício em Benfica, Rio de Janeiro, ícone modernista do ideário de habitação social projetado por Affonso Reidy, não cabe distância. Luiza entende os códigos, procura o contato, se adapta a um sistema diferente do seu: percebe que a "porta aberta" indica receptividade; constata que o corredor é verdadeira área comum, lugar onde "todos são uma família" ${ }^{11}$; ensina matemática para as crianças, empresta sua câmera para os moradores. De saída, o desafio é criar familiaridade, estabelecer laços afetivos, em suma, ser do lugar e evitar os clichês da primeira fotografia.

Sinto-me tão longe do presente próximo e tão perto de um passado qualquer, de cidade pequena e vizinhos queridos.

O apartamento tem vista de torre e ar de casa

Estou acolhida em meio aos pertences da Dona Leda. Faz três meses que ela partiu.

Os objetos ainda quentes, cachorros de porcelana que latem calados na estante.

Imagino como seria a sua vida, junto à família com que agora convivo.

Faço retratos a fim de homenagear os que aqui vivem.

Vejo nos seus olhos uma ternura de agradecimento por meu gesto simples e afável.

Participei da alegria do corredor, parte rua-parte pátio-parte sala, local onde crianças deitam, eu deito, comida se apronta, comparte-se cerveja, música e conversas.

Respeito esta casa como se fosse minha. Ela agora me pertence.22

Se no Pedregulho o desafio consistiu em esquivar-se da imagem-estereótipo da sinuosa fachada modernista, no projeto Península a artista opera a partir da subversão da imagem-marca do condomínio de luxo situado na Barra da Tijuca, Rio de Janeiro. Em suas investidas, Luiza persegue tudo que desmitifique a promessa idílica desse modus vivendi: na série Insulares, fotografa ora um apartamento-padrão, unissex e impessoal, genérico; ora pavimentos em osso, "ruína(s) do que ainda não é". ${ }^{23}$ Imagem versus imagem. Atrai-lhe a luz solar que todo canto invade, "a água marrom do mangue, com uma mancha enorme verde florescente de algas tóxicas", as "espinha de peixe, conchas e formigas (que) se camuflam pela fuligem". ${ }^{24}$ 


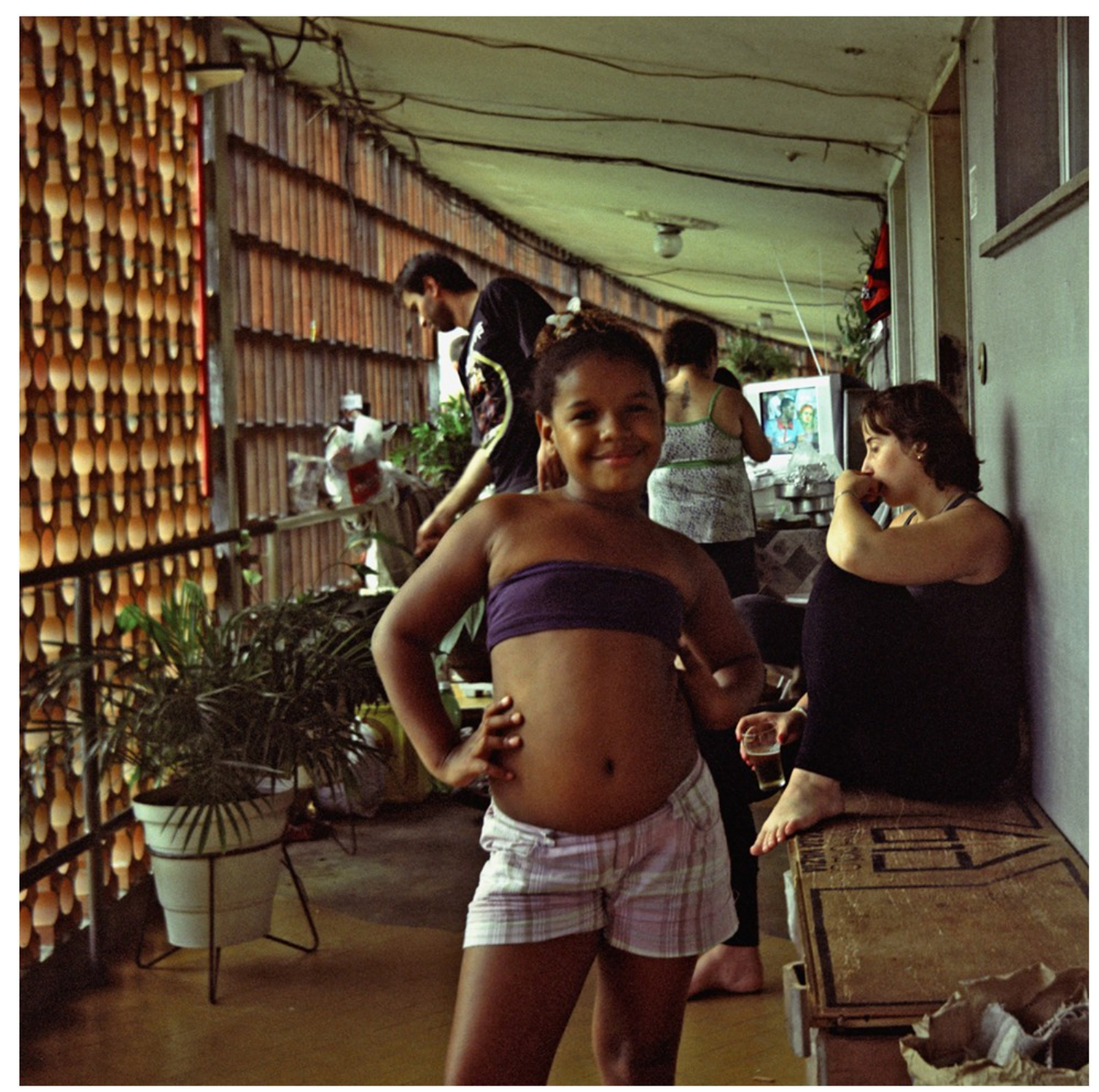

Sem Título (Residência no Pedregulho), Rio de Janeiro, 2009

Tendo em vista a constante ausência de pessoas nas fotografias de Luiza, é preciso se perguntar sobre os seus retratos. Se a artista faz do banal algo "belo enquanto rastro do verdadeiro" 25 , aqui o anônimo torna-se magistral; é a glória do qualquer um de que fala Rancière. Tais presenças, no entanto, parecem ir além. Se as fotografias de Baldan versam sobre o vínculo entre a artista e os lugares, do mesmo modo, em seus retratos o que se vê não são pessoas em destaque, e sim, mais propriamente, imagens da unidade entre o indivíduo e o lugar ao qual pertence. ${ }^{26}$ Nesse amálgama de sujeito e mundo, que desconhece relações hierárquicas, não há por que distinguir figura e fundo; ambos são protagonistas, encontram-se em perfeita integração. Entre eles, há apenas histórias.

O músico tocava bateria vendo o relógio da Central. A moça dava banho no cachorro todas as manhãs na garagem. O outro cão morava no mato por debaixo da piscina, com seus potinhos de comida e água, diferente dos gatos que não eram de ninguém. $\mathrm{O}$ menino sentava nos degraus da portaria para esperar a carona da tia para a escola. $\mathrm{O}$ rapaz pulava do trampolim esperando mergulhar na cidade. Era um dos prédios mais luxuosos do bairro. ${ }^{27}$ 
Luiza não costuma apelar para recursos cênicos. De saída, elimina o uso do tripé, não lança mão do zoom; coloca-se em situações em que, se necessário, move-se para se aproximar ou se afastar do motivo. Trata-se de "trabalhar com os limites e as possibilidades próprias ao corpo"; de forçar a "apreensão do olhar a partir não da intenção de construir uma fotografia de um determinado modo, mas porque se quer observar algo de outra maneira". ${ }^{28} \mathrm{Na}$ verdade, o trabalho de Luiza se concentra embora não se esgote - na pré-produção. Em sua fotografia não há cortes ou aplicação de efeitos a posteriori. Visando preservar a impressão in loco, a atividade de laboratório é direcionada para que a imagem se aproxime o máximo possível da cena original. Vale o enquadramento, as condições de iluminação imprevisíveis e eventualmente adversas. Luiza não usa flash, muito menos faz arranjos de elementos; as coisas são fotografadas de acordo com a sua ocorrência. Interessam-lhe as situações disponíveis, as cenas prontas que o ambiente urbano oferece. Nesses termos, a cidade é seu estúdio. ${ }^{29}$

Este ou aquele, o lugar é a mídia de Luiza, o topos de seu pathos emocional, meio pelo qual abre espaço de manobra, constituindo, intuitivamente, uma vasta paisagem existencial, articulando uma narrativa casual, espécie de filme mudo em que nos vemos em um mundo ermo. Prova disso é a chamada desculpa geográfica, conceito produtivo formulado pela artista para designar os locais utilizados como pretexto para deflagrar os projetos com tempo determinado. Justificativas e proposições iniciais são facilmente descartadas durante a execução do projeto, pois o real propósito do trabalho emerge concomitantemente a seu processo de execução. E, por processo, entenda-se a experiência do lugar. ${ }^{30}$ Não à toa, Luiza fala de "um lugar que pode ser em qualquer lugar", "um lugar que é transformado e que nos transforma ao mesmo tempo". ${ }^{31}$ Refratário por definição a qualquer posição distanciada, o empirismo da artista envolve a constituição de campos de ação processuais definidos pela inscrição do corpo. Nesses termos, cada série encarna uma temporalidade lenta, o tempo suspenso relativo às brechas forçadas no fluxo produtivista do mundo, garantindo, desse modo, a abertura ao imprevisto e o encontro com o outro. ${ }^{32}$ Não obstante, cada projeto se desmembra em diversos trabalhos distintos. Tomada em conjunto, a obra de Luiza se caracteriza, por assim dizer, pela processualidade: antes mesmo de um trabalho terminar, a partir dele outro já se insinua. 


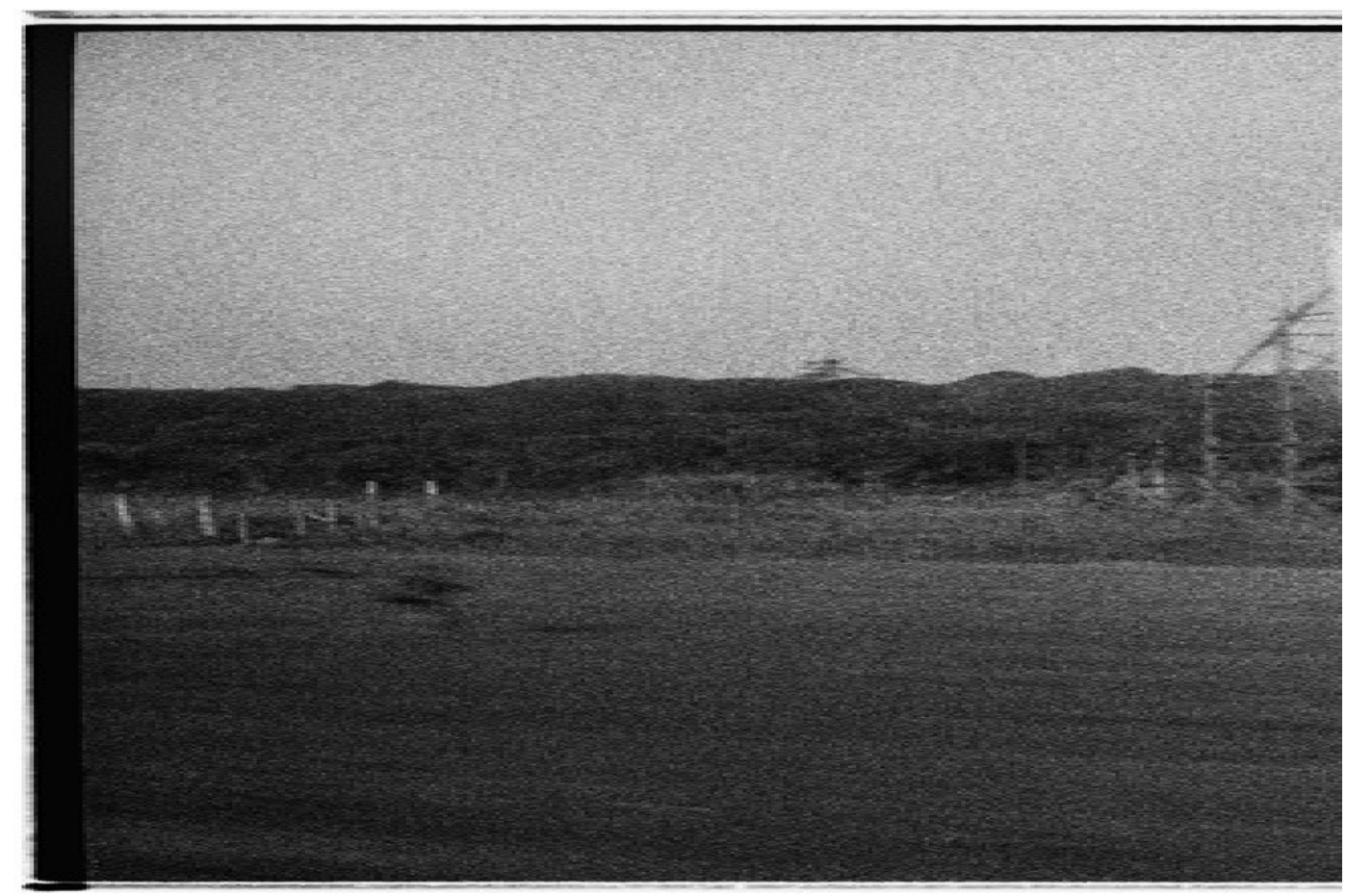

Perabé (frame), 2014-2015, videoinstalação HD, p/b, áudio em 4 canais, 31'10"

Súmulas veladas de tais experiências, cada projeto carrega consigo um tecido de relações sociais: é construção em ato que encontra nexo concomitantemente à vivência; surge da negociação entre intenções prévias e acaso, do "embate entre aquilo que se imagina e o que de fato acontece quando se vive a experiência". ${ }^{33}$ Numa palavra, o lugar se impõe ao trabalho, exige reorientações estratégicas, informa a visualidade, os critérios de seleção e de ordenação das séries; às vezes, contribui na pós-produção, definindo conceitualmente a estrutura visual do trabalho. Nesse sentido, um recurso utilizado é a inversão do ponto de vista, espécie de transposição, na estrutura expositiva, das circunstâncias experimentadas no lugar. ${ }^{34}$ Há ainda outros exemplos, como a exibição de uma carta náutica encontrada na baía de Guanabara durante o processo de realização do projeto Estofo. ${ }^{35}$ No entanto, em pelo menos um projeto, a ideia de experiência é menos codificada do que, efetivamente, estendida à recepção do trabalho. Aproximandose do ato expressivo descrito por Dewey, em Perabé Luiza "assimila e reedita o material objetivo na forma construída de um novo objeto". ${ }^{36}$

\section{Imagem como experiência}

O leitor deve ser levado adiante não meramente ou sobretudo pelo impulso mecânico da curiosidade, não pelo desejo irrequieto de chegar à solução final, mas pela atividade prazerosa do percurso em si. ${ }^{37}$ 
Durante o período da Residência Pivô, no edifício Copan, em São Paulo, Luiza descobre que existe um ponto na cidade de onde é possível ver o mar. Movida pela curiosidade, inicia intensa pesquisa. Entra em contato com a história da fundação de São Paulo, se embrenha na literatura que aborda a travessia da Serra do Mar. Em Perabé - nome de cidade que literalmente significa "caminho do mar" -, a artista sai em busca desse lugar inusitado. A ideia é fazer o trajeto inverso ao dos bandeirantes. Com uma câmera Olympus Trip, sem fotômetro ou pilha, leve, própria para trilhas longas, Luiza passa a empreender frequentes viagens ao longo de vários meses. ${ }^{39}$ Fotografa sem se preocupar com a qualidade da imagem. De alta sensibilidade, o filme PB (ISO 3200) garante a exposição em qualquer luminosidade, ao preço da granulação e da superexposição. Se deixando levar pelo caminho, Luiza adota novas rotas ao conhecer pessoas que the contam histórias ou the dão indicações. Aos poucos, o encontro com o mar se revela inocente, e a busca torna-se outra. Logo, a trama de pontos fixos no mapa se transforma em rede de relações em expansão.

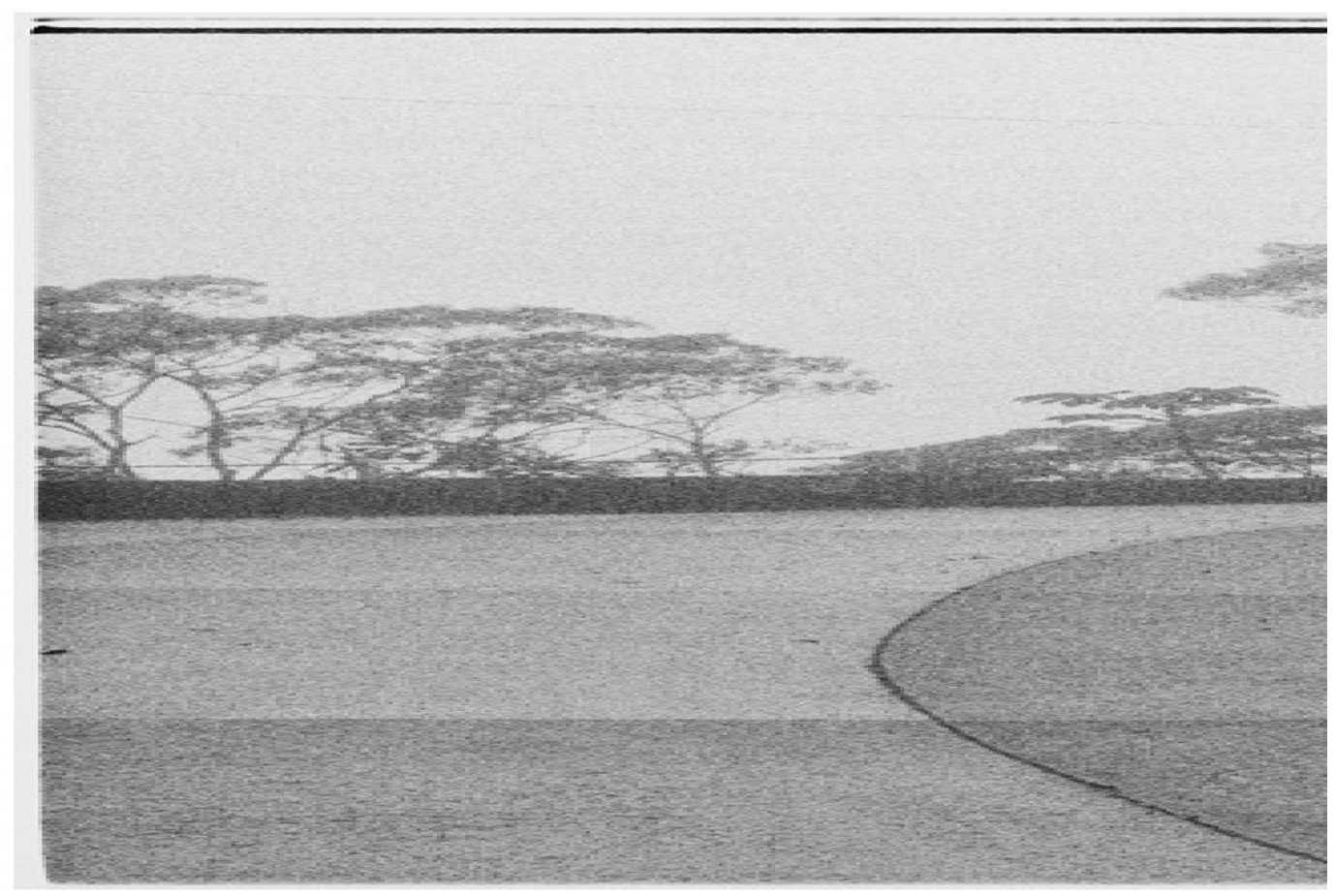

Perabé (frame), 2014-2015, videoinstalação HD, p/b, áudio em 4 canais, 31'10"

Durante os percursos, Luiza anota frases, palavras soltas, expressões singulares com as quais se depara. Exercita, também, a escrita de memória. Ao final, entrelaça seus escritos de grande apelo existencial às diversas fontes literárias pesquisadas: Paulo Prado, Roberto Pompeu de Toledo, Capistrano de Abreu, Hans Staden, a Carta de Pero 
Vaz de Caminha. Antes complemento, com relativa independência, o texto se mescla a um grande conjunto de fotografias em sucessão, muitas contemplativas, outras apenas registros de momentos, importantes porque evidenciados pelos sentidos: o cheiro da maresia, a temperatura ou qualquer evento que tenha prendido "os olhos e ouvidos, despertando o interesse e proporcionando prazer enquanto se olha e escuta". ${ }^{40}$ Videoinstalação que constrói um longo caminho fictício, Perabé não tem propriamente começo, meio e fim; tampouco respeita ordenações cronológicas ou coordenadas geográficas. Disparador do projeto, o mar não constitui clímax ou resolução; aparece e desaparece, permeando o trabalho.

O meu mapa é uma grande recorrência sua, Atlântico. Ainda feto nadava na barriga da mãe. Sou marmífera. Eu queria mesmo era ter nascido na sua beira, no algodoal mais branco do mundo, mas isso seria suicídio. Eu bem que tentei. Em solavancos, sigo o seu rastro em viagens partidas, como tantos tamoios, tijucos, tropeiros e piratas o fizeram de Cabo Frio a Santos.

\section{$[\ldots]$}

De todos os caminhos possíveis, escolho o meu. Tantos trajetos refeitos, pé ante pé sem a menor pista. Rotas automáticas impulsionadas por um fluxo qualquer imposto não sei por quem. E de tanta repetição algo se faz presente. Um canto alto e monótono que interrompe inesperadamente a solidão muda do caminhar frequente. A pedra em que se tropeça e faz despertar para o que há ao redor. $\mathrm{O}$ alarde e o reconhecimento. ${ }^{4}$

Luiza reúne e organiza, condensa o que antes se encontrava difuso e descontínuo no intercurso de suas viagens. Da ordem do cinemático - com vocação, contudo, para agenciar o corpo no espaço -, Perabé é projeção, estrutura em movimento que transforma a experiência na estrada e nas trilhas em nova jornada. É circuito dinâmico de imagens-texto com cadência própria, sequência de fotografias de lugares que servem de ponto de paragem para o olhar consciente, acompanhado pela reflexão incessante que o texto narrado encarna sob a forma do pensamento alto a vagar. Nos termos que remetem à experiência do andarilho, Perabé nos submete a uma expedição introspectiva, sem rumo certo. Se ela é relativa à interação de Luiza com uma determinada área, decerto seu significado transcende qualquer condição regional ou individual. Perabé não é elogio a um lugar, mas uma afirmação do valor do contato afetivo do indivíduo com o mundo. A meu ver, essa é a emoção estética que o trabalho suscita, conferindo-lhe completude e unidade. Aberto às coincidências, o projeto não apenas encontrou nexos e associações durante seu processo de construção ${ }^{42}$, como também, casualmente, entronizou em sua trajetória a noção de desfecho que caracteriza uma experiência ao ser exibido no Centro Cultural São Paulo, marco inicial da primeira estrada do caminho para o mar. 


\section{* Michel Masson é pós-doutor junto ao Programa de Pós-Graduação em Arquitetura da PUC-}

RIO.

* Nas citações em epígrafe, bem como nas demais em idioma estrangeiro, a tradução é do autor do artigo.

${ }^{1}$ SONTAG, S. Sobre fotografia. São Paulo: Companhia da Letras, 2004.

${ }^{2}$ DEWEY, J. Art as experience. New York: Perigee Books, 1980, p. 3.

${ }^{3}$ DEWEY, J. Op. cit., p. 84.

${ }^{4}$ DEWEY, J. Op. cit., p. 24.

${ }^{5}$ DEWEY, J. Op. cit., p. 104.

${ }^{6}$ DANTO, A. A transfiguração do lugar comum: uma filosofia da arte. São Paulo: Cosac Naify, 2005.

${ }^{7}$ KRAUSS, R. "Notes on the Index: Part II". In: KRAUSS, Rosalind E. The originality of the avantgarde and other modernist myths. Massachusetts: The MIT Press, 1986.

${ }^{8}$ BALDAN, L. Petricor, 2011.

9 Em 2003, Luiza se formou em BFA (fotografia e time-based media) e história da arte na Universidade Internacional da Flórida - FIU. Como parte do programa de ensino, cursou disciplina com metodologia pautada na crítica fotográfica, sendo submetida à tarefa semanal de fotografar, revelar, ampliar e discutir sua produção com os demais estudantes.

${ }^{10}$ Luiza Baldan em conversa com o autor, 31/10/2016.

${ }^{11}$ Luiza Baldan em conversa com o autor, 31/10/2016.

12 Segundo a artista em conversa com o autor em 31/10/2016, Becos foi sua "grande escola".

13 Tomo de empréstimo o termo usado por Marc Augé para definir espaços públicos de rápida circulação, despersonalizados, como quartos de hotéis, aeroportos e estações de metrô. AUGÉ, M. Não-lugares: introdução a uma antropologia da supermodernidade. Campinas: Papirus, 1994.

${ }^{14}$ Barthes chama de punctum esse tipo de detalhe casual que punge na foto e lança o observador para além do que a imagem dá a ver. BARTHES, R. A câmara clara: nota sobre a fotografia. Rio de Janeiro: Nova Fronteira: 1984, p. 89.

${ }^{15}$ Em conversa com o autor, em 31/10/2016, Luiza Balda menciona que, por volta de 2003-2004, se muda para Barcelona, Espanha, onde fica desprovida de laboratório fotográfico. Esse período marca uma interrupção de sua atividade artística.

${ }^{16}$ Nesse aspecto, vale a comparação com Rua, série fotográfica de Pablo Lobato realizada com celular ao longo de dois anos em sete países. Ao contrário de Lobato, o interesse de Luiza não se restringe ao registro objetal de esculturas urbanas involuntárias, "composições inusitadas (...) abandonadas pelos pavimentos das ruas (...) arranjos provisórios de objetos" que, nos dizeres de Júlio Martins (s.d.), "se oferecem ao olhar despretensiosamente, mas com uma sofisticação formal notável que emerge da simplicidade, do acaso ou mesmo da distração". MARTINS, J. Depoimento sobre o livro Rua. Disponível em: https://allevents.in/belo\%20horizonte/lan\%C3\%A7amento-dolivro-rua-em-belo-horizonte-pablo-lobato/740540909418366, s.d. Acessado em 13/06/2017.

${ }^{17}$ RANCIÈRE, J. A partilha do sensível: estética e política. São Paulo: Editora 34, 2009, p. 55.

${ }^{18}$ Tais projetos se iniciam por volta de 2012, quando os exercícios de observação cotidianos vinculados aos projetos em andamento são redirecionados para o uso da câmera do celular. Luiza Baldan em conversa com o autor, 31/10/2016.

${ }^{19}$ BALDAN, L. Corta Luz, 2013.

${ }^{20}$ BALDAN, L. Petricor, 2011. 
${ }^{21}$ BALDAN, L. Natal no Minhocão, 2009.

22 Idem.

${ }^{23}$ BALDAN, L. De murunduns e fronteiras, 2010.

24 Idem.

${ }^{25}$ RANCIÈRE, J. Op. cit., p. 50.

${ }^{26}$ Partindo do pressuposto de trabalhar junto aos moradores do Pedregulho, Luiza fez duas propostas. Na primeira, convidou pessoas para posar para ela, com hora marcada e em lugar escolhido por elas a partir de sua relação afetiva com o edifício. Desse modo, Luiza pôde conhecer o edifício pela perspectiva de seus habitantes, em vez de se submeter a uma visita guiada promovida pela associação de moradores. O resultado consistiu em retratos em lugares subjetivamente relevantes, como o local do primeiro beijo, da brincadeira de pique esconde, ou mesmo em cima de uma moto, objeto de sonho de muitos adolescentes. Na segunda proposta, Luiza forneceu aos moradores uma Lubitel, câmera russa analógica de médio formato com disparador, para que eles mesmos se fotografassem. Luiza ampliou cerca de 70 fotografias produzidas ao longo dos dois projetos. No dia de Natal, os retratos foram presenteados aos moradores, enquanto as fotografias coletivas, sem autoria conhecida, foram montadas numa pequena exposição no edifício. Um cenário se mostrou recorrente: várias famílias posaram diante da árvore de Natal na área comum do edifício. Segundo relato de Luiza em conversa no MAM-Rio, em 23/10/2016, a moradora responsável pela montagem anual da árvore Ihe disse: "Minha filha, você precisa vir de longe tirar uma foto para a gente ver de novo que bonito que é esse lugar".

${ }^{27}$ BALDAN, L. Petricor, 2011.

${ }^{28}$ Luiza Baldan em conversa com o autor em 31/10/2016.

${ }^{29}$ Luiza Baldan em conversa com o autor em 31/10/2016.

${ }^{30}$ Em A uma casa de distância da minha, Luiza alia a premissa do exercício de observação a uma road trip em Portugal, propondo-se sair em busca de exemplares do chamado Português Suave, estilo arquitetônico criado pelo arquiteto Raul Lino no início do século XX, transformado nos anos 30 pelo Estado Novo de Salazar em estilo nacionalista. Abandonada a ideia inicial de partir de carro do Porto para Lisboa, Luiza pega a estrada em direção ao litoral norte, indo até a península de Troia, região de restinga submetida nos anos 60 a um processo de remodelação visando transformá-la em um complexo turístico. A despeito dos investimentos pós-período de degradação, permanece esvaziada a maior parte do ano, por conta das condições climáticas austeras e da transferência do turismo para Algarves, na região sul. Uma vez nessa cidade fantasma, falsa arcádia pós-moderna, a artista se hospeda num hotel, na verdade, antigo clube reformado, que serviu de locação para O estado das coisas, do cineasta Wim Wenders, e atualmente é administrado pela cadeia internacional Marriott. Desprendendo-se em parte de sua desculpa arquitetônica inicial, Luiza passa a registrar tudo que the desperta interesse durante a viagem: edificações peculiares nas pequenas cidades de beira de estrada, um píer sobre o areal, um hidrante solitário. No hotel, fotografa a piscina, filma da janela do quarto as ondas vindo de encontro à praia no entardecer, como, em conversa com o autor, em 31/10/2016, ela recorda. Suave vastidão, sem vivalma.

${ }^{31}$ Luiza Baldan em conversa no MAM-Rio, em 23/10/2016.

${ }^{32}$ Luiza Baldan conversa com Ana Kieffer, Anita Schwartz Galeria, 17/04/2017.

${ }^{33}$ BALDAN, Luiza. Entrevista para o Prêmio PIPA. Disponível em: http://www.premiopipa.com/pag/ artistas/luiza-baldan/, s.d. Acessado em: 13/06/2017. 
${ }^{34} \mathrm{Na}$ montagem de Suave, por exemplo, o posicionamento da projeção do vídeo e fotografia em paredes opostas visou remeter à cena encontrada por Luiza no saguão do hotel situado na península de Troia, litoral norte de Portugal: uma fotografia do edifício com ponto de vista na praia, pendurada na parede do hall, situada de frente para o mar.

${ }^{35}$ Montada na Anita Schwartz Galeria, a exposição consistiu em dois ambientes distintos. No primeiro, um amplo salão, foi posicionada uma mesa com uma caixa contendo fotogravuras para serem manuseadas; a parede em frente foi deixada vazia e as demais, usadas para colocar as matrizes, um texto e o mapa. Uma sala menor foi destinada à videoinstalação Suspiro. Segundo conversa com Ana Kieffer, na Galeria, em 17/04/2017, Luiza havia pensado em expor sapatos com intenso odor encontrados nas águas da baía, mas retrocedeu julgando tratar-se de excesso de informação.

${ }^{36}$ DEWEY, J. Op. cit., p. 107-108.

${ }^{37}$ S. T. Coleridge, citado em DEWEY, J. Op. cit., p. 5.

${ }^{38}$ BALDAN, L. Petricor, 2011.

${ }^{39}$ Por ora, Baldan abandonou os exaustivos projetos de residências de longo prazo. Já não é mais preciso - ela argumenta em conversa no MAM-Rio em 23/10/2016 - morar no lugar para falar sobre ele; bastam à artista deslocamentos periódicos, pois as idas e vindas para casa não implicam, necessariamente, perda de conexão. Em relação a tal prática, Luiza, em conversa com o autor em 31/10/2016, informa que faz analogia com Miquel Barceló. Em seus cadernos de África, o pintor espanhol costumava retomar o trabalho, após longos intervalos, no ponto em que havia parado. Luiza Baldan em conversa com o autor, 31/10/2016.

${ }^{40}$ DEWEY, J. Op. cit., p. 4-5.

${ }^{41}$ BALDAN, L. Perabé, 2015.

42 Dentre as coincidências e associações que ocorrem ao longo da execução de Perabé, em conversa no MAM-Rio, em 23/10/2016, Luiza destaca algumas. Por conta da sua escala e decadência, Santos a faz lembrar-se de Campos, lugar de origem de sua família. Na cidade paulista, assim como naquela do norte fluminense, há uma rua chamada Nilo Peçanha em homenagem ao primeiro presidente brasileiro negro, que era campista. Justamente nessa rua, ficava a casa dos pais de Luiza. Além disso, por conta do "mar", Luiza rememora Cabo Frio, cidade em que morou e na época morava sua mãe, de quem se aproxima depois de anos e que, aliás, quase perdera a vida durante seu parto, realizado na água. Cabo Frio é também o lugar que marca o último foco de resistência da Confederação dos Tamoios, aliança de tribos indígenas que congregava tupinambás, guaianás e aimorés, motivada pelos ataques dos portugueses e mestiços vicentinos, liderados por João Ramalho e pelo cacique Tibiriçá que procuravam capturar escravos entre os indígenas para trabalhar nas primeiras plantações de cana-de-açúcar. Em uma das fotografias de Perabé, Luiza registra uma vitrina em que se lê João Ramalho Interiores, que pode ser uma homenagem ao explorador português ou talvez o nome do proprietário. 